\title{
MODERNIDADE E CRISE AMBIENTAL: DAS INCERTEZAS DOS RISCOS À RESPONSABILIDADE ÉTICA
}

\author{
Silvia Maria Santos Matos ${ }^{1}$ \\ Antônio Carlos dos Santos ${ }^{2}$
}

\begin{abstract}
Resumo: O objetivo deste artigo é analisar a crise ambiental, a partir do conceito de modernidade e, levando em consideração a preocupação com a natureza, debater as possibilidades de pensar uma ética da responsabilidade que influencie as práticas da ciência e da política. A discussão tomou como referência diversos autores que examinaram a modernidade e sua relação com o contexto da crise, entendida como resultado do caráter experimental na expansão das ciências e das técnicas. Diante disso, as saídas aqui indicadas se direcionam para caminhos diferentes. $\mathrm{O}$ primeiro envolve uma posição que implica modificar o conjunto dos elementos que caracterizam o processo de modernização da sociedade. O segundo caminho se insere na mesma estrutura do progresso técnico e científico vigente, modificando somente os valores regulativos. Ambas as possibilidades demonstram a necessidade de considerar que as açôes da ciência devem fazer parte das discussóes centrais da política, pois se instalam no contexto político de exercício de uma ética em meio à crise ambiental. Nessa perspectiva, faz-se necessária a criação de novos arranjos institucionais para o debate crítico, sob os mais variados riscos produzidos na sociedade.
\end{abstract}

Palavras-Chave: Crise ambiental. Modernidade. Ética da responsabilidade. Política.

\section{INTRODUÇÁo}

Nas últimas décadas, a tomada de consciência da crise do meio ambiente tem despertado a atenção de diversos países e suscitado importantes discussóes sobre a modernidade, cujos riscos alcançaram proporçôes globais

\footnotetext{
${ }^{1}$ Doutora em Desenvolvimento e Meio Ambiente e pós-doutoranda pelo Programa de Pós-graduação em Desenvolvimento e Meio Ambiente da Universidade Federal de Sergipe, São Cristovão, SE - Brasil. Pesquisadora do Grupo de Pesquisa "Filosofia e Natureza”. E-mail: smsmatos@yahoo.com.br

2 Professor do Departamento de Filosofia e dos Programas de Pós-graduação em Filosofia e de Pósgraduação em Desenvolvimento e Meio Ambiente da Universidade Federal de Sergipe, São Cristovão, SE - Brasil. E-mail: acsantos12@uol.com.br

Doutor em Filosofia pela Université de Paris X (Paris-Nanterre). Coordenador do Grupo de Pesquisa "Filosofia e Natureza".
}

http://dx.doi.org/10.1590/0101-3173.2018.v41n2.11.p197 
intensas que remontam à Revolução Industrial. Esse período pode ser denominado como "modernidade técnica" (BRUSEKE, 2010), em virtude de sua configuração racional (WEBER, 1999) instrumentalizada em seus meios e fins, neutralizada no tempo e no espaço. Ele tem como principal eixo estruturador a ciência e a técnica, que se constituíram através da compreensão e domínio da natureza, e que, apesar dos avanços nos campos da ciência e tecnologia, da economia e da administração, dentre outros, também produziram consequências imprevistas, a tal ponto que os artefatos tecnológicos têm atualmente o poder de destruição da humanidade. Entretanto, não somente nas armas se constitui o perigo da técnica, mas também nos softwares e no consumo desenfreado, os quais visam a promover o conforto de uma vida boa para a humanidade, na qual toda ação é justificada.

No meio ambiente, as consequências dessa modernidade têm dado sinais bastante evidentes de mudanças físicas no cenário mundial, a exemplo das alteraçôes no clima, derretimento das geleiras e avanços no nível do mar, cheias e inundaçôes, esgotamentos dos recursos hídricos, secas e desertificação, entre outros. Todos esses eventos já não são mais raros e estão se tornando rotineiros. O agravamento desses problemas pode comprometer a sobrevivência de, pelo menos, parte da população do planeta, num futuro mais ou menos longínquo. Estes são problemas diretamente relacionados ao processo de modernizaçáo e ao desenvolvimento tecnoindustrial, cujo princípio organizador é a produção e a distribuição de bens, constituindo uma primeira fase da modernidade. Autores como Beck (2010) e Giddens (1991) apontam para o aparecimento de uma segunda fase da modernidade, marcada pelo surgimento da "sociedade de risco", cujo eixo norteador não é apenas a distribuição de bens, mas de riscos, principalmente ecológicos.

As mudanças físicas de que tratamos no parágrafo anterior são um reflexo da ordem que constitui o fundamento da modernidade, o qual, de acordo com Latour (1994), caracteriza-se pela separação radical entre a natureza e a cultura. Entretanto, o mesmo autor questiona que, se a modernidade foi assim tâo eficaz em seu trabalho de separação, por que ela está enfraquecendo e nos impedindo de sermos modernos, de fato?

A análise da modernidade feita por Bruno Latour consiste numa tentativa de desnaturalização do processo de separação ontológica que a identifica, ou seja, o autor desdobra a construção ideológica que fundamenta o desenvolvimento da razáo ocidental e a critica como uma ilusão que jamais chegou a penetrar até mesmo nas práticas mais centrais ou nos espaços mais conceitu- 
ados da cultura europeia e americana. Afirma que "jamais fomos modernos", porque, na constituição da modernidade sempre existiram, concomitantemente, a purificação ou separação e a hibridação, uma vez que, quanto mais nos proibimos de pensar nos híbridos, mais seu cruzamento se torna possível: este é o paradoxo dos modernos, conclui o autor (LATOUR, 1994, p. 16-17).

Dessa forma, Latour questiona: como poderíamos completar, enfim, a purificação das ciências das sociedades, quando os próprios modernizadores causam a proliferação dos híbridos, graças à mesma constituição que nega sua existência? (LATOUR,1994, p. 129-130).

A crise ambiental com a qual nos deparamos provoca na sociedade a reflexão sobre a necessidade de mudanças de ordem ideológica e de valores da própria sociedade, exigindo repensar a ética do progresso que orienta a técnica, ao menos desde o início da modernidade. Tal crise é evidenciada, por inerência, como um fenômeno da crise da própria modernidade e do processo de modernização, fundamentados na separação do homem da natureza, na racionalizaçáo e no progresso como desenvolvimento. Assim, este artigo tem por objetivo analisar a crise ambiental, a partir do conceito de modernidade, como um fenômeno resultante dos riscos produzidos no processo de modernização e, levando em consideração a preocupação com a natureza, debater as possibilidades de pensar uma ética da responsabilidade que influencie as práticas da ciência e da política.

O presente texto está dividido em três partes: na primeira, é abordado o conceito de modernidade, a qual se evidencia como uma era fundamentada na razão enquanto elemento central no domínio e na apropriaçáo da natureza, cujas consequências indicam uma era de incertezas e de riscos complexos. $\mathrm{Na}$ segunda parte, são examinados fatos e aspectos da ciência e da técnica e sua influência na provocação da crise ambiental. Por fim, na terceira parte, são analisados argumentos que possibilitam pensar a açáo de uma ciência e de uma política com responsabilidade ética, diante da natureza.

\section{MODERNIDADE: O QUE É E COMO SE CARACTERIZA}

$\mathrm{Na}$ obra $O$ discurso filosófico da modernidade, Habermas retoma teorias de diversos pensadores e afirma que Hegel foi o primeiro filósofo que desenvolveu um conceito claro de modernidade. Segundo Habermas, Hegel emprega tal conceito, antes de tudo, em contextos históricos, como conceito 
de época: os "tempos modernos", os quais, por volta do século XVII, designam os três séculos precedentes. A descoberta do "novo mundo", o Renascimento e a Reforma são os três grandes acontecimentos que, entre os séculos XIV e XV, constituem o limiar histórico entre a época moderna e a medieval. Depois, essas expressões perderam seu sentido puramente cronológico e assumiram a significação de uma época orientada para o futuro, isto é, uma era aberta ao novo, que há de vir. Assim, interpretando Hegel, Habermas assevera que o fato de uma modernidade sem modelos ter de estabilizar-se com base nas cisóes por ela produzidas causa uma inquietude, que Hegel concebe como "a fonte da necessidade da filosofia." (HABERMAS, 2000, p. 24).

Para Latour, todas as definiçôes de modernidade apontam, de uma forma ou de outra, para a passagem do tempo. Através do adjetivo moderno, assinalamos um novo regime, uma aceleração, uma ruptura, uma revoluçáo do tempo. Quando as palavras "moderno, modernização e modernidade" aparecem, definimos, por contraste, um passado arcaico e estável (LATOUR, 1994, p. 15).

A modernidade é, inevitavelmente, uma experiência que retira da tradiçâo o seu sentido e a sua razão de ser e que está destinada a tornar-se, a seu modo, também uma experiência tradicional, a partir do momento em que se impóe como um novo imperativo com caráter próprio.

A modernidade não pode e não quer tomar dos modelos de outras épocas os seus critérios de orientação: ela tem de extrair de si mesma a sua normatividade. A modernidade vê-se referida a si mesma, sem a possibilidade de apelar para subterfúgios. Isso explica a suscetibilidade da sua autocompreensão, a dinâmica das tentativas de "afirmar-se", que seguem sem descanso até os nossos dias (HABERMAS, 2000, p. 12).

De acordo com Hegel, interpretado por Habermas (2000), o princípio que caracteriza a modernidade ou os novos tempos é a liberdade da subjetividade, segundo o qual todos os aspectos essenciais presentes na totalidade espiritual se desenvolvem para alcançar o seu direito. Assim, esse princípio determina as manifestaçóes da cultura moderna. Primeiramente, isso vale objetivamente para a ciência, que, ao mesmo tempo, desencanta a natureza e liberta o sujeito. Dessa forma, todos os milagres foram contestados, pois a natureza é agora um sistema de leis conhecidas e reconhecidas, no qual o homem é livre pelo conhecimento e domínio da natureza. 
No caminho do discurso filosófico, Habermas retoma as definiçóes de modernidade de Max Weber e apresenta o conceito de modernização ${ }^{3}$, como uma abstração plena de consequências, a qual separa a modernidade de suas origens, ou seja, a Europa dos tempos modernos, para estilizá-la em um padrão neutralizado no tempo e no espaço, de processos de desenvolvimento social e geral. Eis como Habermas concebe a modernização:

Um conjunto de processos cumulativos e de reforço mútuo: à formação de capital e mobilização de recursos; ao desenvolvimento das forças produtivas e ao aumento da produtividade do trabalho; ao estabelecimento do poder político centralizado e à formaçáo de identidades nacionais; à expansão dos direitos de participação política, das formas de vida e da formaçáo escolar formal; à secularização de valores e normas etc. (HABERMAS, 2000, p. 5).

Conforme Latour, a modernização, mesmo tendo destruído a ferro e sangue quase todas as culturas e naturezas, tinha um objetivo claro. Modernizar permitia distinguir claramente as leis da natureza exterior e as convençóes da sociedade. Um front coerente e contínuo de revoluçôes radicais, nas ciências, nas técnicas, na administração, na economia, na religiâo. Verdadeira pá de trator, atrás da qual o passado desaparecia para sempre, mas na frente da qual se abria, ao menos, um futuro (LATOUR,1994, p. 129).

Ao tratar da sociedade moderna, Weber destaca que somente na civilização ocidental apareceram fenômenos culturais dotados de um desenvolvimento "universal", tanto em seu valor como no seu significado. Para Weber, as sociedades modernas constituíram-se a partir de um longo processo de desenvolvimento de racionalização que influenciou a formação de instituiçóes, como o Estado, e de ordens sociais, como o capitalismo. A diferença do tipo moderno de economia, o capitalismo, em relação aos tipos desenvolvidos anteriormente é, essencialmente, "a organização rigorosamente racional do trabalho sobre o fundamento da técnica racional." (WEBER, 1999b, p. 531). Da mesma maneira, o Estado racional, caracterizado pela burocratização e autonomização de suas funçóes e regras cada vez mais separadas de outras ordens sociais, como a religião, só ocorreu na modernidade. Apenas na modernidade

\footnotetext{
${ }^{3} \mathrm{~A}$ origem da modernização está ligada às grandes transformaçôes econômicas e industriais iniciadas na Europa, a partir do século XVII e XVIII. Entendido como um processo de transformaçáo centrado na ideia de progresso e no desenvolvimento técnico ilimitado, o conceito é claramente ocidental e, muitas vezes, surge associado a outros, como industrialização, urbanização e desenvolvimento (GIDDENS, 1991).
} 
ocidental existe a ciência num estágio de desenvolvimento que atualmente conhecemos como "válido", cujo tratamento racional e sistemático, por especialistas treinados, não existiu em outras culturas (WEBER, 1999a, p. 1; 3).

Esse processo de modernização se move por si próprio e opera somente com as leis funcionais da economia e do Estado, da técnica e da ciência, as quais se fundem em um sistema pretensamente imune a influências. $\mathrm{O}$ modo de produção nas sociedades capitalistas industrialmente desenvolvidas exige permanentemente a renovação de técnicas para ser operado, de maneira a proporcionar aumento da produtividade no trabalho e mais conforto à existência humana, através do consumo.

Assim, a racionalização que Weber aborda é um processo de transformação, em longo prazo, de estruturas sociais cuja verdadeira intenção é a de manter uma dominaçáo, do homem e da natureza, ocultada por uma referência aos imperativos técnicos. Nesse contexto, a política fica reduzida a atender às necessidades funcionais e de regulação do sistema e, por sua vez, segundo Dupas, adquiriu um caráter negativo, orientando sua ação para evitar riscos que poderiam pôr o sistema em perigo e não para realizar finalidades práticas que interessem diretamente ao cidadão (DUPAS, 2006, p. 87).

É em razão dessas características que as instituições modernas, sob diversos aspectos fundamentais, são únicas e, por isso, apresentam certas descontinuidades com as culturas e os modos de vida pré-modernos. Weber (1982) enfatiza que o destino de nossos tempos é marcado pela racionalização, intelectualização e, acima de tudo, pelo "desencantamento do mundo" .

Um dos aspectos mais óbvios que separa a era moderna de qualquer período anterior é seu extremo dinamismo, como afirma o sociólogo inglês Anthony Giddens. O mundo moderno é um "mundo em disparada”. Não só o ritmo da mudança social é muito mais rápido que em qualquer sistema anterior, como a amplitude e a profundidade com que ela afeta práticas sociais e modos de comportamento preexistentes são maiores (GIDDENS, 2002, p. 22).

\footnotetext{
${ }^{4}$ Significa principalmente que não há forças misteriosas incalculáveis, mas que podemos, em princípio, dominar todas as coisas pelo cálculo, e que já nâo precisamos recorrer aos meios mágicos, a fim de dominar ou implorar aos espíritos, como fazia o selvagem, para quem esses poderes misteriosos existiam. Os meios técnicos e os cálculos realizam o serviço. Isso significa racionalização (WEBER, 1982, p. 165).
} 
Dinamismo e descontinuidade são características próprias da modernidade. De acordo com Giddens, a modernidade nos últimos séculos é um fenômeno de dois gumes. Por um lado, o desenvolvimento das instituiçóes sociais modernas e sua difusão em escala mundial criaram oportunidades bem maiores para os seres humanos gozarem de uma existência segura e gratificante, em relação a qualquer sistema pré-moderno. Por outro lado, ainda segundo Giddens, o que não foi previsto pelos principais pensadores que analisaram a sociedade é que o desenvolvimento das forças de produção teria um potencial destrutivo de larga escala em relação ao meio ambiente (GIDDENS, 1991, p. 16).

Não apenas a ameaça de confronto nuclear, mas a realidade do conflito militar forma também o "lado sombrio" da modernidade, nos séculos XX e XXI. Se um conflito entre grandes potências eclodisse, poderia eliminar completamente a humanidade. A possibilidade de conflito nuclear condiciona perigos que nenhuma geração anterior teve que enfrentar (GIDDENS, 1991, p. 112). Outro pressuposto do autor é o de que, por mais que tenha havido progresso na negociação internacional e no controle das armas, o risco de uma guerra maciçamente destrutiva permanecerá, uma vez que náo se conseguiria erradicar o conhecimento técnico estabelecido e os armamentos podem ser reconstruídos a qualquer momento (GIDDENS, 2002, p. 12).

Confiança e segurança, risco e perigo, caracterizam unicamente as condições da modernidade. Pessoas que vivem em países industrializados e, em certa medida, em qualquer lugar hoje, estão geralmente protegidas contra alguns perigos enfrentados rotineiramente em tempos pré-modernos, como as forças da natureza. Por outro lado, novos riscos e perigos, tanto locais quanto globais, são criados humanamente pelos próprios mecanismos da modernidade. O risco é uma condição com a qual a sociedade moderna se defronta, e se diferencia do perigo no sentido de que o primeiro pode ser previsto e calculado como uma condição específica da sociedade moderna. Dessa maneira, a confiança em relação ao risco é termo que passa a existir somente nessa sociedade, uma vez que são criados sistemas burocráticos de segurança, como forma de controle desses riscos. Já o perigo não pode ser previsto, a exemplo de, nas condiçôes da modernidade, existir o perigo de ocorrência de uma guerra nuclear ou de acidentes em uma usina nuclear.

Giddens também destaca que especificar a confiança em culturas pré-modernas não é dizer que cenários tradicionais eram psicologicamente aconchegantes, enquanto os modernos não o são. Os perigos que enfrentamos na 
modernidade não derivam mais primariamente do mundo da natureza. É claro que ciclones, terremotos e outras catástrofes naturais ainda ocorrem. Mas, em sua maior parte, nossas relações com o mundo físico são radicalmente diferentes daquelas das épocas anteriores, especialmente nos setores industrializados do globo.

À primeira vista, os perigos ecológicos que enfrentamos atualmente podem parecer semelhantes às vicissitudes da natureza encontradas na era pré-moderna. Entretanto, as ameaças ecológicas de hoje são resultado do conhecimento organizado, mediado pelo impacto da industrialização sobre o meio ambiente material. São partes do que Giddens (1991) chama de um novo perfil de risco, introduzido pelo advento da modernidade. Os riscos ambientais com os quais lidamos, por serem globais, desafiam a noçáo de previsibilidade, ou seja, os riscos globais de grandes consequências catastróficas que todos nós corremos atualmente são elementos característicos de descontrole da modernidade, em função da possibilidade construída por sistemas de conhecimentos humanos de autodestruição da vida sobre a terra. Nesse contexto, a ciência e, sobretudo, a técnica desempenham papel central como eixos estruturadores dessa condição.

\section{A CRISE AMBIENTAL COMO UMA CONSEQUÊNCIA DA MODERNIDADE: O PAPEL DA CIÊNCIA E DA TÉCNICA NA PRODUÇÁo DE RISCOS NA SOCIEDADE}

Grosso modo, a crise da modernidade se expressa através da emergência de questôes que dizem respeito ao risco global, representado pela possibilidade de catástrofes ambientais generalizadas. A ideia de que a degradação ambiental se relaciona com atividades humanas como a indústria, que se desenvolveu diretamente através dos avanços da ciência e da tecnologia, vem sendo divulgada desde o século XIX. Com a detecção de efeitos globais provocados pelas bombas atômicas lançadas sobre o Japão, na Segunda Guerra Mundial, começa a ser mais bem delineada a ideia de que eventos ocorridos em determinado local podem se estender muito além deste, desencadeando efeitos destrutivos em longo prazo.

Porém, é somente a partir dos anos 60 do século XX que a noção de uma crise global do meio ambiente, que ameaçaria toda a espécie humana, começa a ganhar força, provocando uma tomada de consciência dos limites da capacidade da natureza diante do progresso técnico e do crescimento econô- 
mico. Com isso, iniciaram-se as primeiras reaçôes, manifestaçôes e estudos a respeito do problema, constituindo-se como marcos dessa caminhada. ${ }^{5}$

Nesse contexto, compreender a constituição da crise ambiental é entendê-la como fruto da expansão do papel da ciência e da técnica, cujo objetivo sempre foi o de ampliar não só o domínio sobre a natureza, mas também o domínio sobre outros homens. Isso explica o caráter de compreensão e controle que constitui a natureza da ciência moderna, em uma passagem da obra técnica e ciência como ideologia. Habermas (1968, p. 50-51) assim destaca:

A ciência em virtude do seu próprio método e de seus conceitos projetou e fomentou um universo no qual a dominaçáo da natureza se vinculou com a dominação dos homens - vínculo que tende a atingir fatalmente este universo enquanto todo. A natureza compreendida e dominada pela ciência surge de novo no aparelho de produção e de destruição, que mantém e melhora a vida dos indivíduos e, ao mesmo tempo, os submete aos senhores do aparelho.

A dominação manifesta-se não só mediante a tecnologia, mas na própria tecnologia que proporciona legitimação ao poder, o qual, por sua vez, assume em si todas as esferas da cultura (HABERMAS, 1968, p.49). Assim, a compreensão da ciência e da técnica expressa racionalização e essência da sociedade moderna, uma vez que todo aparato tecnológico representa muito mais que instrumentos ou ferramentas, mas um modo de vida, concebido em uma razão sistêmica (HABERMAS, 2012) com poder autônomo, no qual "o

\footnotetext{
5 O livro Primavera silenciosa, de Rachel Carlson, foi um marco no alerta dessa crise, ao denunciar o impacto do uso de produtos químicos sobre o meio ambiente. A autora chama a atenção para os efeitos não calculados dos pesticidas, como contaminação de partes subterrâneas dos sistemas fluviais e a permanência dessas substâncias no solo (CARLSON, 2010). Em abril de 1968, um grupo de 30 indivíduos de dez países reuniu-se em Roma, instigados por um empresário industrial italiano, para debater assuntos relacionados à crise atual e futura da humanidade (ODUM, 1988). Esse grupo incluía cientistas, economistas, humanistas, funcionários públicos nacionais e internacionais, o qual se denominou "O Clube de Roma”. O grupo patrocinou uma série de relatórios, com base também em estudos já desenvolvidos anteriormente. O primeiro destes contemplava os limites do crescimento, em 1972, o qual advertia que a humanidade corria para o desastre, se ela năo renunciasse rápida e radicalmente à sua trajetória atual de crescimento (FORRESTER, 1971 apud SACHS, 2007). Esse relatório denunciou a obsessão da sociedade com o crescimento econômico, em todo nível - individual, familiar, empresarial, nacional -, cuja meta era de se tornar cada vez maior, mais rico e mais poderoso, sem se considerar o custo final do crescimento exponencial. Nos anos 80 , foram igualmente divulgados efeitos globais como aqueles gerados pelo acidente nuclear na Usina de Chernobyl e a emissão de CO que intensifica o efeito estufa e aniquila com importantes ciclos vitais, além da decomposição da cama² da de ozônio. Graves acidentes químicos e nucleares ocorridos desde os anos 50 do século passado, em diversos países, consolidaram efetivamente a noção de uma crise global do meio ambiente.
} 
homem náo passa de um meio ou de um instrumento [...] capturado como objeto ou a matéria-prima ao se instalar na rede de produção tecnológica." (DOMINGUES, 2004, p. 164).

No entanto, o mesmo autor ressalta que, na era moderna, a história da tecnologia era vista como um dispositivo ou meio a serviço dos homens, quando da descoberta da máquina a vapor e do motor a explosão. Com a descoberta do transistor, que posteriormente deu lugar ao chip, cuja base revolucionou a indústria eletroeletrônica, as comunicaçôes, a informática, e consequentemente a engenharia genética e os segmentos da biotecnologia, vemos que a técnica, na atualidade, se tornou a própria razão da sociedade moderna. Logo, não só a ameaça dos artefatos tecnológicos que têm o poder de destruição da humanidade causa temor, mas também a perspectiva que se abre em relaçáo ao poder da técnica com capacidade de reengenhar e mesmo de produzir o próprio homem, o que gera igualmente uma ameaça à própria essência da constituição humana (DOMINGUES, 2004).

Como já mencionado, foi a partir da Segunda Guerra Mundial e da ocorrência de catástrofes ecológicas de grandes proporçôes, como a de Chernobyl, além de outras incertezas as quais envolvem as tecnologias modernas, que se percebeu como o homem não tem mais controle sobre a técnica. $\mathrm{O}$ que se questiona aqui fortemente não é a ciência valorizada pelo seu método e experimento como meios adequados para se chegar ao conhecimento seguro e verdadeiro (SANTOS, 2012), todavia, o caráter experimental da própria modernidade (GIDDENS, 1996), cujas inovaçôes e discussôes científicas carregam um potencial cada vez maior de impacto em nossa vida diária, que, ao mesmo tempo, estaria se tornando cada vez mais problemática. Descobertas científicas e o uso de tecnologias são questionados, de sorte que o perfil da "imparcialidade" da ciência se torna cada vez mais questionado (LENZI, 2006, p. 169).

Contudo, conscientes dos riscos provocados pelos efeitos indesejados da ciência e da técnica produzidos na modernidade, convém se pensar numa postura responsável diante das possibilidades postas pela ciência. Nesse contexto, Bruseke (2010) destaca a necessidade da reflexão científica sobre a modernização. Em face de tais circunstâncias, os cientistas e os políticos se encontram numa posição-chave, como intérpretes do perigo. 


\section{A RESPONSABILIDADE DA CIÊNCIA E DA POlítiCA DIANTE DA CRISE AMBIENTAL}

Propostas de enquadrar moralmente a atividade científica, após as guerras mundiais, sob a égide da Organização das Naçôes Unidas, fracassaram. Já é sabido que se discute a necessidade de um código de conduta para a ciência, o qual seja de aceitação universal. Berlinguer salienta que a ciência tem, como aspecto essencial que a caracteriza, a liberdade e o seu rigor metodológico. Parte-se do pressuposto de que a busca pela compreensão é inerente à própria natureza humana, e criar obstáculos a ela se constituiria numa regressão antropológica. Assim como a arte, a filosofia, a literatura, o conhecimento científico não pode progredir sem criatividade e, dessa forma, não pode se manifestar sem liberdade (BERLINGUER, 2003, p. 193).

Weber, no seu ensaio "A ciência como vocação", afirma que o trabalho da ciência está preso ao curso do progresso, e que sua essência é destituída de valores, tendo apenas uma conotação prática (WEBER, 1982, p. 163, 174). Porém, essa racionalização da ciência não denota a aquisição de um conhecimento maior e geral das condiçóes sob as quais vivemos. Significa principalmente que podemos, em princípio, dominar todas as coisas pelo cálculo. Assim, na sua essência, a ciência contribui para a tecnologia do controle da vida, calculando os objetivos externos, bem como as atividades do homem (WEBER, 1982, p. 165, 177).

Weber ainda destaca que, mesmo quando se toma uma posição em relação a um problema de valor, é inevitável o uso de meios para se pôr em prática as convicçóes que se buscam. Entretanto, para o mesmo autor, se continuarmos fiéis às nossas convicçóes, chegaremos às conclusóes finais que subjetivamente têm sentido. É isso o que, pelo menos em princípio, podemos realizar, enfatiza o autor. Nesse sentido, Leal registra que, para Weber, uma das possibilidades de "emancipação do indivíduo moderno", em face das ordens racionais do mundo, é procurar assumir uma posição "consistente" e responsável como homem de vocação política e científica ou simplesmente como homem, em seus diversos modos de ser moderno (LEAL, 2008, p. 24). Por isso, Weber defende que, apesar de a ciência estar presa ao curso do progresso, o cientista pode desenvolver uma ética da responsabilidade, orientada por valores.

Assim, a ética da responsabilidade, para Weber, implica que a escolha valorativa seja esclarecida e consciente, como pressuposto que regerá a própria conduta, como uma condição inevitável para o "homem civilizado", no mun- 
do desencantado. Weber ressalta ainda que um professor que cumpre o seu dever de provocar o autoesclarecimento e um senso de responsabilidade estará a serviço de forças "morais". Nessas condiçôes, afirma o autor, a ciência é uma "vocação" digna para alguém (WEBER, 1982, p.179).

Portanto, a despeito de toda essa liberdade própria da ciência, é importante considerar que não se deve isentar a mesma de utilizar o princípio da precaução ${ }^{6}$, o qual deve norteá-la, não para evitar as descobertas da verdade, mas para informar ou mesmo alertar a sociedade. $\mathrm{Na}$ observação do novo comportamento da natureza, é responsabilidade dos cientistas alertarem a sociedade para precaver-se e para o Estado instituir os limites a serem impostos, através de políticas regulatórias. No entanto, convém ressaltar que há questionamentos segundo os quais esse princípio possa prever com exatidão as consequências ambientais das atividades humanas. Para Giddens e Beck, o princípio da precaução por si só não seria suficiente para lidar com a complexa relação entre ciência e riscos ecológicos (LENZI, 2006, p. 175-176).

Compreender o papel da ciência na sociedade moderna significa compreender também que a ciência tem função importante no desenvolvimento de modelos que auxiliem na previsão e análise dos riscos. Lacey enfatiza que a ciência fornece não só a possibilidade de desenvolvimento tecnológico, vital ao movimento da modernidade, mas, do mesmo modo, fornece igualmente, por meio do seu instrumental teórico, a possibilidade racional do entendimento dessa própria característica fundante de nosso tempo (LACEY, 1998, p. 87).

Essas ideias convergem com o pensamento de Larrère e Larrère, segundo os quais a ciência, na sua diversidade, se encontra no centro da crise ambiental e é responsabilizada pelos atentados ao meio ambiente. Por outro lado, ainda conforme os mesmos autores, espera-se que o saber científico detecte o mal e encontre a respectiva solução. Os homens políticos, a opinião pública e, mais ainda, os media esperam em geral da ciência respostas simples, quer se trate de saber se o priāo nos ameaça, se o clima se altera, ou se um novo Chernobyl é possível. Quer-se igualmente saber a que se poderão atribuir essas ameaças, a quem imputar responsabilidade (LARRÈRE; LARRÈRE, 1997, p. 254).

\footnotetext{
${ }^{6}$ Surgido na Alemanha nos anos 70, associado à proteçấo da camada de ozônio, torna-se o princípio fundador do direito do meio ambiente, com o relatório Bruntland sobre o desenvolvimento sustentável, em 1988. Também chamado princípio da prudência, enuncia-se de maneira a enquadrar e impedir certas açōes potencialmente perigosas, sem esperar que o perigo seja cientificamente definido com toda certeza (LARRÈRE; LARRÈRE, 1997).
} 
Os mesmos autores ressaltam que a responsabilidade social do cientista consiste em se interrogar sobre a maneira como as atividades científicas se inscrevem num contexto social, político e ambiental. Trata-se de antecipar, tanto quanto possível, as consequências que as investigaçôes empreendidas podem ter, e não a de se considerar satisfeito por ter respondido a alguns concursos e ter escrito alguns artigos para revistas internacionais.

Portanto, não basta ao cientista atender a processos burocráticos de funcionamento da ciência, no caminho incessante da superespecialização. Sobretudo, deverá responsabilizar-se pelas consequências subsidiárias que poderão ocorrer, a partir de suas descobertas.

Nesse contexto, ao propor seu princípio responsabilidade, Jonas (2006) sustenta que o grau de conhecimento dos cientistas tem que ser maior e, se não se sabe o que vai acontecer, não se deve agir. A ética deve invadir os espaços de pesquisa científica e a sociedade deve se informar e intervir. $\mathrm{O}$ mesmo autor afirma ainda:

O horizonte relevante da responsabilidade é fornecido muito mais pelo futuro indeterminado do que pelo espaço do agir essencial, então a moralidade deve invadir a esfera do produzir, da qual ela se mantinha afastada anteriormente, e deve fazê-lo na forma de política pública. Nunca antes a política pública teve que lidar com questôes de tal abrangência e que demandassem projeçóes temporais táo longas. De fato, a natureza modificada do agir humano altera a natureza fundamental da política. (JONAS, 2006, p. 44).

O homem público de hoje tem uma capacidade maior de previsão, em função da técnica, o que aumenta ainda mais a responsabilidade. É necessário que o estadista tenha uma nova postura. A responsabilidade dele é maior. Não é possível essa modificação, no plano individual (JONAS, 2006, p. 41 e 54).

Apesar da denúncia da utopia da técnica, que perpassa sua obra, a postura política de Jonas se inclina para uma solução autoritária dos problemas ambientais, a ponto de considerar que uma ditadura como a que houve na União Soviética estava mais bem armada do que a democracia para enfrentar a crise ambiental. Nesse sentido, exclui o debate público que examinaria os riscos, amparando-se na heurística do medo, como proposta de uma ética da responsabilidade que antecipa a catástrofe. Dessa forma, ignora a racionalidade argumentativa e retira a capacidade de informar açóes precisas positivas, deixando-lhe apenas o alcance negativo (LARRÈRE; LARRÈRE, 1997). 
Numa perspectiva republicana, Domingues (2004), ao discutir a relação entre ética, ciência e tecnologia, indicando os caminhos e os desdobramentos percorridos pela técnica na era moderna, através da interpretação do pensamento de diversos pensadores da filosofia, conclui que é necessário humanizar a técnica. $\mathrm{O}$ autor ressalta que, por sua natureza, a ciência não tem a capacidade de gerar ética, uma vez que trabalha com fatos e não com valores, sendo estes mais do que uma cognição, dependendo de tradições e sentimentos, por isso, ele afirma não ser nada fácil ajustar à ética a ciência e a tecnologia. Entretanto, alerta que se poderia pensar na responsabilidade do cientista e do tecnólogo. Argumenta também que a aliança entre cientista e tecnólogo náo basta, pois se corre o risco de serem levados em conta, em seu embate, interesses políticos e econômicos. Então, faz-se necessário estender a ética à sociedade, dando ensejo ao que o autor chama de ética comunitária, fundada em valores socialmente compartilhados, como a liberdade, a justiça e a responsabilidade, ou seja, uma postura fundada no republicanismo.

Por outro lado, o mesmo autor registra ainda que a ética sozinha não pode dar conta da sua missão de humanizar a ciência e a tecnologia, pois não tem a capacidade de regrar as açóes. A ética deve servir-se de outras instâncias ou esferas sociais, como o direito, o Estado e a política, utilizando-se do seu poder coercitivo, na instituição dos limites nos usos e excessos da técnica.

Ao abordar a necessidade de religar o éthos da ciência, relançando a ética republicana, Domingues (2011) defende que o caminho para uma ética da ciência é a sua transformação em coisa pública e matéria de política pública, vencendo o isolamento do cientista e lançando-o na arena política. Para o mesmo autor, o que permite pôr os hommes de science como intelectuais públicos é uma questão prática, antes de ser uma questão teórica, e depende tão-só de que eles entrem ou tenham entrado na cena pública, ao serem solicitados ou por a terem invadido, como indivíduo ou agrupamento social. Trata-se do cientista comprometido com as causas da ciência e com as coisas do mundo, como Galileu, Darwin e Einstein, apontados como exemplos pelo autor. Domingues ainda destaca:

Em um mundo em que a atividade intelectual e científica tornou-se fragmentada e ultra-especializada e, ao mesmo tempo, uma ação coletiva e um trabalho em equipe, a depender de políticas públicas e de contratos firmados com os governos e as sociedades, o desafio é quebrar o isolamento do cientista e trazê-lo para a cena pública. Assim, poderá dar sua opinião e oferecer sua expertise toda vez que for convocado, quando ocupará a cena pública, somando a sua opiniáo à de outros experts e, resultando do con- 
junto um novo tipo de intelectual. Novo, porque não está em jogo voltar ao que era, recuar até a Renascença e relançar o intelectual generalista. Trata-se antes de forjar uma nova figura justamente o intelectual público e sua especialidade ou o intelectual público especializado que consegue transcender seu campo disciplinar. Junto com ele um novo éthos da atividade intelectual será formatado: o éthos da inteligência coletiva e da responsabilidade social, e uma nova ética irá acompanhar as suas ações. (DOMINGUES, 2011, p. 482-483).

Assim, sendo a ciência transformada em "coisa pública", no sentido da res publica, poderá estender-se à atividade intelectual, para além do mundo da política. Poderá ampliar-se de modo mais exigente do que a ética republicana tradicional, visto que as mudanças de escala do processo de conhecimento, com custos econômicos, sociais, ecológicos e morais altíssimos, exigem do cientista a responsabilidade social de suas açôes. Por essa razão, levando-se em consideração a seriedade com que se deve tratar a ciência, esta não deve estar unicamente sob o controle dos cientistas (DOMINGUES, 2011).

Dessa forma, trata-se de vencer o fosso existente e reconhecer os mesmos aspectos dos campos de conhecimento como prática social, caracterizados por certa porosidade entre as disciplinas, permitindo o compartilhamento de experiências e mesmo sua remodelagem, ao fim e ao cabo. É, pois, antes mesmo de uma questão epistêmica, uma questão de cultura que está em jogo, exigindo uma nova visão das coisas e uma nova atitude do letrado e do cientista. De acordo com Domingues, nesse ponto é que entra a ética, e duas serão suas tarefas: religar o éthos fraturado da ciência e atar as duas pontas em que se desenvolve a atividade intelectual moderna, junto com os dois tipos de intelectual que as acompanham, as ciências humanas e sociais e o intelectual humanista (hommes de lettres) e as ciências exatas e naturais (hommes de science) (DOMINGUES, 2011, p. 483).

Bruno Latour, ao refletir sobre a representação científica e sobre a representação política, argumenta que "inventaram nosso mundo moderno, um mundo no qual a representação das coisas através do laboratório encontra-se para sempre dissociada da representação dos cidadãos através do contrato social." (LATOUR, 1994, p. 33). De um lado, o sujeito de direito; do outro, o objeto da ciência, a força natural, o mecanismo. Para Latour, os porta-vozes políticos deverão representar a multidão calculadora de cidadãos; os porta-vozes científicos deverão de agora em diante representar a multidão muda e material dos objetos. Nesse sentido, o autor propóe que as ciências entrem na 
democracia, de sorte a redefinir a vida pública como "composição progressiva de um mundo comum.” (LATOUR, 2004a, p. 39).

\section{CONSIDERAÇÓES FINAIS}

Compreender essas proposituras, dadas as circunstâncias do problema da crise ambiental, significa questionar-se diante do fato de os cientistas serem a única voz na tomada de decisão em relação aos problemas científicos e tecnológicos concernentes ao controle e transformação da natureza, os quais a sociedade aceita de maneira táo pouco crítica. Por isso, é de fundamental importância evidenciar esse aspecto, uma vez que riscos e perigos são debatidos somente quando as práticas tecnológicas já estão sedimentadas. Quanto à política, esta não deve limitar-se às paixôes e interesses na vida pública, contudo, precisa incluir a ciência, que age no campo do isolamento e da "imparcialidade científica", no processo democrático, pois numa "sociedade de risco" (BECK, 2010) como a nossa, as açôes da ciência devem fazer parte das discussóes centrais da política.

As propostas de Latour e Domingues, analisadas aqui, são importantes, pois se inserem num contexto político de exercício de uma ética em meio à crise ambiental. Tais consideraçóes a esse respeito nos mostram duas coisas em relação ao cenário da crise ambiental. A primeira, fundamentada nas ideias de Latour, envolve uma posição revolucionária, a qual implica modificar o conjunto dos elementos que envolveram o processo de modernização da sociedade. De acordo com seu pensamento, esse caminho consiste em "ecologizar”, não no sentido defendido atualmente por ativistas e políticos, mas no sentido amplo de construir uma política que reconheça que não separamos as questôes da natureza e da cultura. O viés "ecologizador" propôe reatar o "nó górdio" separado pelas estruturas e sistemas, através de redes que conectem, ao mesmo tempo, a natureza das coisas e o contexto social. Para Latour, a tarefa da política recomeça da estaca zero, realçando que foi preciso mudar completamente a fabricaçáo de nossos coletivos para absorver o cidadão do século XVIII e o operário do século XIX. Será necessária uma transformação equivalente, para abrir espaço para os não-humanos criados pelas ciências e pelas técnicas, conclui o autor. Em entrevista ao jornal $O$ Globo, o autor des-

\footnotetext{
7 Pressupốe que os cientistas estão livres de terem de responder pelas consequências sociais de suas descobertas.
} 
taca a diferença no seu pensamento entre os conceitos que envolvem a ideia de "modernizar" e "ecologizar":

O importante é que haja uma alternativa a modernizar, que não seja arcaica, reacionária. Que seja progressista, mas de uma outra forma, não modernista. Um problema complicado hoje, sobretudo no Brasil. Mas é complicado por todo o lado, na França também. Qualquer dúvida posta sobre a modernização se diz que é preciso estancar a frente pioneira, de crescer, voltar ao passado. Isso é impossível. É preciso inovar, descobrir novas formas, e isso se parece com a modernização. Mas é uma modernização que aceita seu passado. E o passado foi uma mistura cada vez mais intensa entre os produtos químicos, as florestas, os peixes, etc. Isso é "ecologizar". É a instituição da prática e não da teoria. (O GLOBO, 28 dez. 2013).

Nesse sentido, Latour enfatiza que, no lugar de uma ciência dos objetos e de uma política de sujeitos, deveríamos dispor de uma ecologia política de humanos e não-humanos. De acordo com o autor, essa interação não é somente desejável, mas necessária. É ela quem vai permitir preencher o coletivo de seres dotados de vontade, de liberdade, de palavra e de existência reais (LATOUR, 2004a, p. 120).

Entendemos que essa proposta é complexa por demasiado e, segundo o próprio Latour, não há tradição política para tal, visto que a política está organizada somente para os humanos. Contudo, tendo em vista o estágio de modernidade radicalizada (GIDDENS, 1991) no qual a sociedade se encontra, uma segunda proposta a essa situação de crise amplamente debatida por diversos autores se insere na mesma estrutura do progresso técnico e científico vigente, modificando somente os valores regulativos. Tal proposta implica uma responsabilidade ética coletiva, uma vez que a produção de novos riscos cada vez mais complexos requer, do mesmo modo, a existência de práticas responsáveis de igual intensidade. É claro que a ideia de responsabilidade coletiva não significa a proibição absoluta de pesquisas que envolvam riscos e perigos, no entanto, é imperiosa a criação de novos arranjos políticos e institucionais para o debate crítico. Essa situação pressupóe também que se criem condiçóes de levar o conhecimento sobre os mais variados riscos produzidos na sociedade.

Acreditamos que esse caminho já deu alguns sinais de que começou a ser trilhado, tanto no campo científico quanto no campo político, a exemplo das conferências mundiais sobre o meio ambiente e o desenvolvimento, a institucionalização, por parte dos governos de alguns países, de políticas e órgãos para tratar da questão ambiental. No campo da ciência e tecnologia, pesquisas 
e produtos que se voltam para o uso mais responsável dos recursos naturais. Contudo, esses sinais precisam ser disseminados, de maneira a se tornar uma prática ampla, contínua e inerente às atividades humanas.

MATOS, S. M. S.; SANTOS, A. C. Modernity and the ecological crisis: from uncertainty of risk to ethical responsibility. Trans/form/ação, Marília, v. 41, n. 2, p. 197-216, Abr./Jun., 2018.

\begin{abstract}
The purpose of this article is to analyze the environmental crisis in terms of the concept of modernity and, taking into account a concern for nature, discuss an ethics of responsibility that can influence the practices of science and politics. The discussion takes as a reference several authors who have analyzed modernity and its relation to the context of the crisis, which is understood as a result of the experimental character of the expansion of science and techniques. The solutions presented here are directed along different paths. The first involves a position that implies modifying all elements of the modernization of society. The second path fits into the structure of existing technical and scientific progress, but advocates modifying regulative values. Both possibilities demonstrate the need to consider that the actions of science should be part of core policy discussions, as they fall within the political context of the exercise of an ethical position amidst the environmental crisis. It is therefore necessary to create new institutional arrangements for critical debate, under the conditions of the various risks produced in society.
\end{abstract}

KEYwords: Environmental crisis. Modernity. Ethics of responsibility. Politics.

\title{
REFERÊNCIAS
}

BECK, U. Sociedade do risco: rumo a uma outra modernidade. Tradução de Sebastiāo Nascimento. Rio de Janeiro: Editora 34, 2010.

BERLINGUER, G. A ciência e ética da responsabilidade. In: NOVAES, A. (Org.) $O$ homem máquina: a ciência em tempo de crise. São Paulo: Companhia das Letras, 2003. p. 191-211.

BRUSEKE, F. J. A modernidade técnica: contingência, irracionalidade e possibilidade. Florianópolis: Insular, 2010.

. A lógica da decadência: desestruturação sócio-econômica, o problema da anomia e o desenvolvimento sustentável. Belém: CEJUP, 1996.

CARLSON, R. Primavera silenciosa. Tradução de Claúdia Sant'Anna Martins. São Paulo: Gaia, 2010. 
DUPAS, G. O mito do progresso: ou o progresso como ideologia. São Paulo: Editora UNESP, 2006.

DOMINGUES, I. Ética, ciência e tecnologia. Revista Kriterion, v. 109, p. 159-174, 2004. - O intelectual público, a ética republicana e a fratura do ethos da ciência. Revista Scientiae Studia, v. 9, n. 3, p. 463-485, 2011.

FEYRABEND, P. K. A ciência em uma sociedade livre. Tradução de Vera Jocelyne. São Paulo: Editora UNESP, 2001.

GIDDENS, A. Modernidade e identidade. Tradução de Plínio Dentzien. Rio de Janeiro: Jorge Zahar, 1991.

. As consequências da modernidade. Tradução de Raul Fiker. São Paulo: Editora UNESP, 2002.

HABERMAS, J. Técnica e ciência como ideologia. Tradução de Artur Morão. Lisboa: Edições 70, 1968.

. O discurso filosófico da modernidade. Tradução de Luiz Sérgio Repa e Rodnei Nascimento. São Paulo: Martins Fontes, 2000.

- Teoria do agir comunicativo. Tradução de Luiz Sérgio Repa e Rodnei Nascimento. São Paulo: WMF Martins Fontes, 2012. V. 2.

JONAS, H. O princípio responsabilidade: ensaio de uma ética para a civilização tecnológica. Tradução de Marijane Lisboa e Luiz Barros Montez. Rio de Janeiro: Contraponto, 2006.

KURZ, R. Modernidade autodevoradora. Folha de S. Paulo, São Paulo, 14 jul. 2002. Caderno Mais.

LACEY, H. Valores e atividade cientifica. São Paulo: Editora FAPESP, 1998.

LARRÈRE, C. Duas filosofias de proteção à natureza. Tradução de Antônio Carlos dos Santos. In: SANTOS, A. C. (Org.). Filosofia e natureza: debates, embates e conexões. São Cristóvão: Editora UFS, 2008. p. 184-199.

Atualidade do contrato natural. In: SANTOS, A. C; BECKER. Evaldo (Org.). Entre o homem e a natureza: abordagens teórico-metodológicas, Porto Alegre: Redes, 2012.

. ; LARRÈRE, R. Do bom uso da natureza: para uma filosofia do meio ambiente. Tradução de Armando Pereira da Silva. Lisboa: Editora Instituto Piaget, 1997.

LATOUR, B. Jamais fomos modernos. Tradução de Carlos Irineu da Costa. Rio de Janeiro: Editora 34, 1994.

- Politicas da natureza: como fazer ciência na democracia. Tradução de Carlos Aurélio Mota de Souza. São Paulo: Editora EDUSC, $2004 a$. 
Por uma antropologia de centro. Tradução de Renato Sztutman. Revista Mana, v. 10, n. 2, p. 397-414, 2004b.

. Natureza e política. Jornal O Globo, Rio de Janeiro, 28 dez. 2013. Disponível em: http://oglobo.globo.com/blogs/prosa/posts/2013/12/28/antropologo-frances-brunolatour-fala-sobre-natureza-politica-519316.asp. Acesso em: 14. nov. 2014.

LEAL, E. M. C. Racionalização e liberdade em Max Weber: possibilidades de emancipação do indivíduo contemporâneo. São Cristóvão: Editora UFS, 2008.

LENZI, C. L. Sociologia ambiental: risco e sustentabilidade na modernidade. Bauru-SP: Editora EDUSC, 2010.

NOVAES, A. O espírito recusa habitar sua obra. In: experiência do pensamento. São Paulo: Editora SESC, 2010. (Org.). Mutaçóes: a

ODUM, E. P. Fundamentos de ecologia. Tradução de António Manuel de Azevedo Gomes. 4. ed. Lisboa-Portugal: Fundação Calouste Gulbenkian, 1988.

SACHS, I. Rumo à ecossocioeconomia: teoria e prática do desenvolvimento. São Paulo: Cortez, 2007.

SANTOS, A. C. Em torno da ética ambiental. In: ; BECKER, E. (Org.). Entre o homem e a natureza: abordagens teórico-metodológicas. Porto Alegre: Redes, 2012. p. 35-45.

WEBER, M. A ciência como vocação. In: GERTH, H. H.; MILLS, C. W. (Org.). Ensaios de sociologia. Tradução de Waltensir Dutra. Revisão técnica de Fernando Henrique Cardoso. 5. ed. Rio de Janeiro: LTC, 1982. p. 154-183.

. Categorias sociológicas fundamentais da gestão. In: Economia e sociedade: fundamentos da sociologia compreensiva. Traduçáo de Regis Barbosa e Karen Barbosa. Revisão técnica de Gabriel Cohn. 4. ed. Brasília: Editora Universidade de Brasília, 1999a. V. 1. Cap. II.

Sociologia da dominação: seção sociologia do Estado. In: Economia e sociedade: fundamentos da sociologia compreensiva. Tradução de Regis Barbosa e Karen Barbosa. Revisão técnica de Gabriel Cohn. Brasília: Editora Universidade de Brasília, 1999b. p. 517-580. V. 2. Cap. IX.

. A ética protestante e o espírito do capitalismo. 14. ed. São Paulo: Biblioteca Pioneira de Ciências Sociais, 1999c.

Recebido: 30/11/2015

Aprovado: 05/12/2016 